\section{Molluscum contagiosum: an unusual complication of tattooing}

Molluscum contagiosum is a common viral disease of the skin. The causative virus, from its size, shape, fine structure, cytoplasmic site of replication, and characteristic inclusion body, appears to be a member of the pox group. Transmission is thought to occur by direct contact, though the incubation period is not known and innoculation experiments have failed. Although any infective condition might theoretically be innoculated by tattooing, in practice the only diseases that have been reported are pyogenic infection, syphylis, tuberculosis, serum hepatitis, and one case of viral warts. ${ }^{1}$

\section{Case report}

A 20-year-old man presented in September 1981. Seven months earlier he had had a tattoo professionally performed on his left upper arm with a single needle, using carbon, scarlet lake, and chlorinated copper pigments. Within three months of the tattooing a crop of seven lesions of molluscum contagiosum localised to the area of tattoo performed with carbon pigment had appeared. These had persisted until the time of consultation (figure). Direct microscopy of an unstained curetted lesion on a slide confirmed the diagnosis of molluscum contagiosum. A similar tattoo performed professionally on his right upper arm three years earlier had had no sequelae. He had had no other serious illnesses or skin diseases in the past apart from four common warts present on the palm of his right hand for four years. There was no family history of atopic disease. No treatment was given, and the lesions disappeared spontaneously within six months.

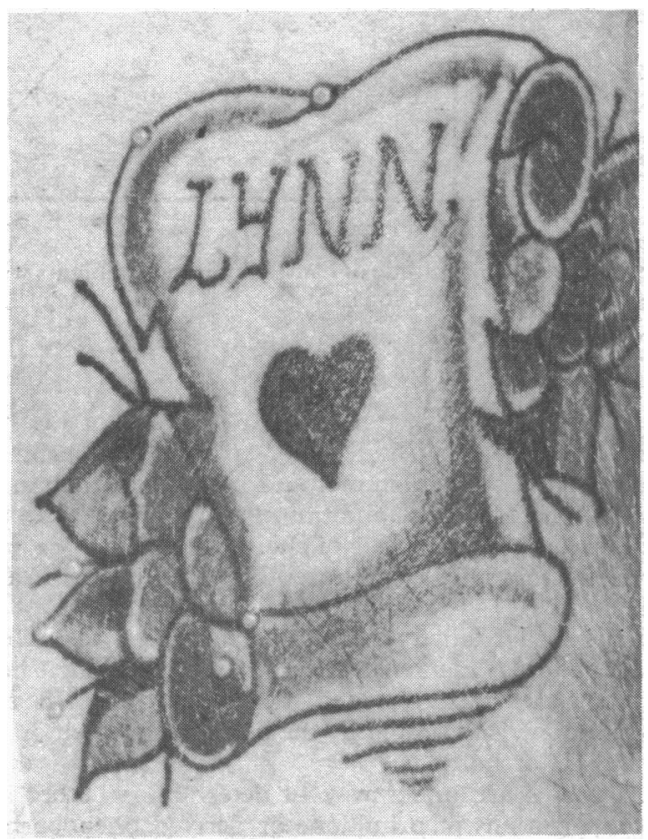

Molluscum contagiosum localised to area of tattoo performed with carbon pigment.

\section{Comment}

In this patient the virions of molluscum contagiosum were presumably innoculated at the time of tattooing and must have been present within the tattoo pigment, which consisted of charcoal suspended in ammoniacal solution containing phenol. To date no similar cases have been reported, which suggests that a particular host environment is required to establish the growth of molluscum contagiosum.

There is some clinical evidence that molluscum contagiosum is spread by direct contact. Seven patients under the care of one surgeon were infected with molluscum contagiosum at the site of operation. ${ }^{2}$ Three women attending a Turkish bath in Sheffield recently developed multiple lesions of molluscum contagiosum at the sites where common salt was rubbed in, suggesting that the salt contained the virus particles (unpublished observation). There have been few reports of molluscum contagiosum affecting more than one member of a family, 34 however, again suggesting that a particular host environment is required. Molluscum contagiosum is thought to occur more commonly in atopic people, though there are only isolated case reports to confirm this and there is dispute over whether the lesions of molluscum contagiosum affect involved or uninvolved areas of active atopic dermatitis. ${ }^{5}$

This isolated appearance of molluscum contagiosum occurring as a result of professional tattooing, localised to one pigment of the tattoo, warrants further investigation into the host environment required for the establishment of this virus.

1 Scutt RWB. The medical hazards of tattooing. Br F Hosp Med 1972;8: 194-202.

${ }^{2}$ Paton EP. Seven cases in which operation wounds were infected with molluscum contagiosum. Westminster Hospital Report 1909;16:11-5.

${ }^{3}$ Calvert JW. Molluscum contagiosum. Arch Dermatol 1972;106:601.

4 Overfield TM, Brody JA. An epidemiological study of molluscum contagiosum in Ankorage, Alaska. F Pediatr 1966;69:640-2.

5 Block SH. The association of molluscum contagiosum and infantile eczema. Med $\mathcal{~}$ Aust 1972;2:626-7.

(Accepted 26 May 1982)

Rupert Hallam Department of Dermatology, Royal Hallamshire Hospital, Sheffield S10 2JF

I S FOULDS, MB, MRCP, senior registrar

\section{Hypocalcaemia-induced epilepsy during lactation}

Hypocalcaemia is a rare but well-recognised cause of grand mal convulsions ${ }^{1}$ and may come to light only as a result of routine biochemical screening. In the present case grand mal convulsions occurred due to hypocalcaemia after a prolonged period of lactation.

\section{Case report}

A 28-year-old woman presented with a history of four grand mal fits within the previous month. During this period she had felt unusually tired and had suffered from generalised headaches, poor memory, and paraesthesiae in the hands and legs. There was no history of birth trauma, head injury, or epilepsy. She had given birth to her first child by caesarean section in February 1980 and had subsequently been breast feeding up to the time of admission eight months later.

Her father suffered from grand mal epilepsy and her sister had petit mal seizures. She was the youngest of four sisters, all of whom had achieved much greater academic success than her.

On examination she was stocky, being $160 \mathrm{~cm}$ in height (smaller than her sisters) and weighing $57.2 \mathrm{~kg}$. Her teeth showed a considerable number of minor enamel defects. Chvostek's sign and Trousseau's phenomenon did not occur. The rest of the clinical examination was normal.

The results of investigations were as follows: haemoglobin concentration $12.1 \mathrm{~g} / \mathrm{dl}$; bicarbonate $28 \mathrm{mmol}(\mathrm{mEq}) / 1$; calcium between 1.45 and 1.54 mmol 15.8 and $6.16 \mathrm{mg} / 100 \mathrm{ml})$ on several occasions; phosphate 1.89 $\mathrm{mmol} / 1(5.85 \mathrm{mg} / 100 \mathrm{ml})$; alkaline phosphatase $490 \mathrm{IU} / 1$; albumin $42 \mathrm{~g} / 1$; total protein $74 \mathrm{~g} / \mathrm{l}$; magnesium $0.69 \mathrm{mmol} / 1(1.68 \mathrm{mg} / 100 \mathrm{ml})$; and parathyroid hormone $<0.1 \mu \mathrm{g} / 1$ (normal range $0 \cdot 1-0.73 \mu \mathrm{g} / \mathrm{l}$ ). A cyclic adenosine monophosphate stimulation test yielded positive results. Autoantibodies were absent on screening, and chest and skull $x$-ray films and a computed tomogram were normal, with no sign of intracranial calcification. Cerebrospinal fluid was at a pressure of $120 \mathrm{~mm}$ water and of normal constitution. Electroencephalography showed moderate bilateral abnormalities with paroxysmal features. Psychological testing yielded an IQ of 81 with poorer than expected verbal and non-verbal memory function.

Primary hypoparathyroidism was diagnosed, and she was treated initially with intravenous'calcium gluconate and then maintained on $1 \alpha$-hydroxycholecalciferol $2 \mu \mathrm{g}$ daily and a high-calcium diet. The serum calcium concentration returned to normal. Anticonvulsants were stopped, and she remained free of fits.

\section{Comment}

Her fits were thought to be due to hypocalcaemia rather than idiopathic epilepsy because, firstly, the plasma calcium concentration was sufficiently low to cause convulsions; secondly, the symptoms of hypocalcaemia, such as paraesthesiae, had begun at the time of the first convulsion; and, thirdly, she remained completely free of fits without anticonvulsant medication once the hypocalcaemia had been corrected. The absence of frank tetany and of Trousseau's phenomenon and Chvostek's sign is unusual in severe hypocalcaemia but not unknown. ${ }^{2}$ 
The main interest in this case is that the patient's fits started only towards the end of a prolonged period of lactation, during which calcium losses would be expected to increase. ${ }^{3}$ We speculate that lactation was a major factor in inducing the convulsions since it may have reduced an already low plasma calcium concentration to epileptogenic levels. A further possibility is that she had a familial tendency to epilepsy that became manifest only in the hypocalcaemic state. Many neurologists do not perform routine biochemical screening in patients presenting with epilepsy: although it may not be justifiable economically to measure plasma calcium concentrations in every patient with epilepsy, we suggest that it is wise to exclude hypocalcaemia in any patient who presents with convulsions during lactation, even if there is a family history of epilepsy.

${ }^{1}$ Simpson JA. The neurological complications of hypoparathyroidism. Brain $1952 ; 75: 76-90$.

2 O'Donovan DK. The diagnosis of latent tetany with observations on the effect of calciferol. Br Med $\mathcal{F} 1948$;ii:900-2.

${ }^{3}$ Fourman P, Royer P, Levell MJ, Morgan BM. Calcium metabolism and the bone. Oxford: Blackwell, 1968:62-4.

(Accepted 3 fune 1982)

Department of Neurology, Radcliffe Infirmary, Oxford

R A HARRAD, MA, MRCP, senior house officer (now at Western Ophthalmic Hospital, London NW 1)

P G E KENNEDY, PHD, MRCP, registrar (now at National Hospital for Nervous Diseases, Queen Square, London WC1)

\section{Double-blind controlled study of primidone in essential tremor: preliminary results}

Essential tremor is a common, monosymptomatic disorder for which no predictable and completely satisfactory drug treatment is available. ${ }^{1}$ Primidone, a well-established anticonvulsant, has been reported to be highly effective, ${ }^{23}$ but this has been based on only uncontrolled clinical observations. We report the preliminary results of a doubleblind placebo-controlled study of primidone in essential tremor obtained using an objective recording technique.

\section{Patients, methods, and results}

We studied 11 patients with moderate to severe essential tremor aged 15-82 (mean 57) years. Mean duration of symptomatic tremor was 10.6 (range 4-24) years. The patients were not taking any other medication. Primidone and placebo were given in randomised order, according to a cross-over design, for five weeks each. Two patients received both primidone and placebo for two weeks only. Primidone was started at $62.5 \mathrm{mg}$ daily and increased by $62.5 \mathrm{mg}$ every day up to a maximum of $250 \mathrm{mg}$ three times a day.

At the end of each five-week regimen tremor was assessed under standardised conditions by using piezoresistive linear accelerometers (ENDEVCO $7265 / 10$ ) attached at the dorsum of each hand, which were maintained outstretched and pronated with the arms supported to the wrists. Derived signals were computed off-line using a spectrum analyser, as described. ${ }^{4}$ Measurements were taken as the root mean square magnitude of acceleration and frequency $(\mathrm{Hz})$ of the dominant peak(s) in the spectrum. The unit of acceleration was referred to earth's gravity $\left(g=981 \mathrm{~cm} / \mathrm{s}^{2}\right)$. Only data derived from the hand that was more severely affected while placebo was being taken were used for statistical analysis. When the recordings of tremor had been completed blood samples were taken for assay of serum primidone and phenobarbitone concentrations. Statistical analysis of the data was performed using Wilcoxon's test for paired differences.

The frequency of the dominant peak of the tremor of the more affected hand ranged between 4.6 and $8.15 \mathrm{~Hz}$ (median $5.95 \mathrm{~Hz}$ ) and the magnitude from 11.02 to $675.29 \mathrm{mg}$ (median $30.55 \mathrm{mg}$ ). When the difference in magnitude was calculated as the absolute change value primidone was significantly superior to placebo $(p<0.01)$. In 10 patients the magnitude of tremor was lower when they received primidone compared with placebo (figure). The median reduction of the magnitude produced by primidone was $65.99 \%$ of the placebo value (range $12 \cdot 7-98 \cdot 7 \% ; p<0 \cdot 01$ ). No significant difference in the frequency of tremor was evident during primidone and placebo treatments.

Owing to dose-related side effects only seven patients achieved the maximum permitted dosage of primidone. The mean daily dosage for the whole group was 590 (range 125-750) mg daily. Serum concentrations of phenobarbitone ranged between 5 and $87 \mu \mathrm{mol} / \mathrm{l}$ (median $44 \mu \mathrm{mol} / \mathrm{l}$ ) and of primi- done between 18 and $100 \mu \mathrm{mol} / 1$ (median $49 \mu \mathrm{mol} / 1$ ). Side effects occurred with primidone in six patients and consisted of a variable combination of sedation, tiredness, nausea, and giddiness; these were attenuated with selfreduction of dosage. In two patients, who were severely affected, tremor was reduced by more than $90 \%$ of control values to within the range of physiological tremor (figure). These patients did not experience any side effects while taking the maximum doses of primidone.

Subsequently 10 patients were put on maintenance treatment with primidone and followed up for a minimum of six months while taking the drug. All maintained satisfactory improvement.

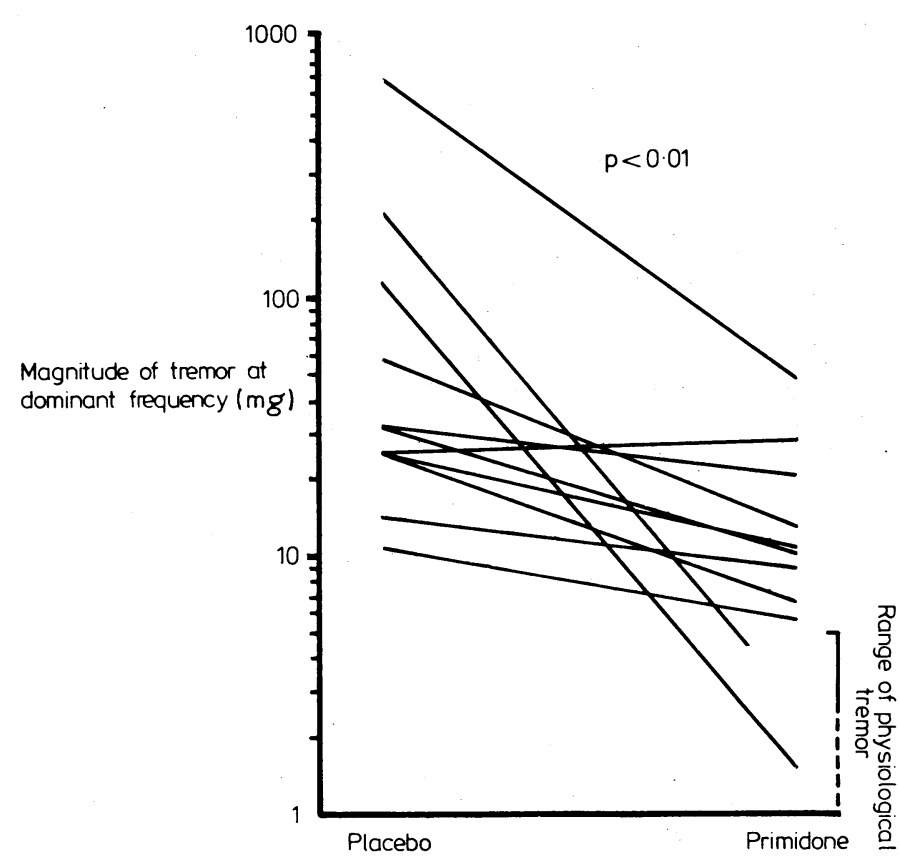

Effect of primidone on magnitude of hand tremor in 11 patients with essential tremor (figures are root mean squares).

\section{Comment}

Our results support the findings of others ${ }^{2} 3$ that primidone consistently improves essential tremor and may be of value in long-term symptomatic control of this condition. It may represent an alternative to propranolol, hitherto the drug of choice in this disorder, particularly in patients in whom beta-adrenoceptor-blocking drugs are contraindicated.

A previous study ${ }^{5}$ failed to show any significant effect of phenylethylmalonamide, a major metabolite of primidone, in essentia tremor; it remains to be established, therefore, whether the tremorlytic effect of primidone is mediated by the parent drug itself or by derived phenobarbitone, or both.

Further studies are under way to determine whether a range of plasma concentrations of primidone or derived phenobarbitone may be established correlating with clinical effect.

${ }^{1}$ Murray TJ. Essential tremor. In: Barbeau A, ed. Disorders of movement. Lancaster: MTP Press, 1981:151-70.

2 O'Brien MD, Upton AR, Toseland PA. Benign familial tremor treated with primidone. Br Med $\mathcal{f} 1981 ; 282: 178-80$.

3 Chakrabarti A, Pearce JMS. Essential tremor: response to primidone. f Neurol Neurosurg Psychiatry 1981;44:650.

4 Calzetti S, Findley LJ, Gresty MA, Perucca E, Richens A. Metoprolol and propranolol in essential tremor: a double-blind controlled study. f Neurol Neurosurg Psychiatry 1981 ;44:814-9.

5 Calzetti S, Findley LJ, Pisani F, Richens A. Phenylethylmalonamide in essential tremor. A double-blind controlled study. F Neurol Neurosurg Psychiatry $1981 ; 44: 932-4$

(Accepted 28 May 1982)

Regional Centre for Neurology and Neurosurgery, Oldchurch Hospital, Romford, Essex

L J FINDLEY, MB, MRCP, consultant neurologist

MRC Neuro-otology Unit, National Hospital, Queen Square, London WC1N 3BG

S CALZETTI, MD, research fellow 